\title{
Development of cost-effective phasor measurement unit for wide area monitoring system applications
}

\author{
V. Vijaya Rama Raju1, K. H. Phani Shree², S. V. Jayarama Kumar ${ }^{3}$ \\ ${ }^{1}$ Electrical and Electronics Engineering Department, Gokaraju Rangaraju Institute of Engineering and Technology \\ (GRIET), Hyderabad, India \\ ${ }^{2,3}$ Electrical and Electronics Engineering Department, Jawaharlal Nehru Technological University Hyderabad (JNTUH), \\ Hyderabad, India
}

\begin{tabular}{l} 
Article Info \\
\hline Article history: \\
Received Nov 9, 2020 \\
Revised May 20, 2021 \\
Accepted Jun 11, 2021
\end{tabular}

Keywords:

Phasor measurement unit Smart grid

Synchrophasor technology

Wide area monitoring system

\begin{abstract}
Sustained growth in the demand with unprecedented investments in the transmission infrastructure resulted in narrow operational margins for power system operators across the globe. As a result, power networks are operating near to stability limits. This has demanded the electrical utilities to explore new avenues for control and protection of wide area systems. Present supervisory control and data acquisition/energy management systems (SCADA/EMS) can only facilitate steady state model of the network, whereas synchrophasor measurements with GPS time stamp from wide area can provide dynamic view of power grid that enables supervision, and protection of power network and allow the operator to take necessary control/remedial measures in the new regime of grid operations. Construction of phasor measurement unit (PMU) that provide synchrophasors for the assessment of system state is widely accepted as an essential component for the successful execution of wide area monitoring system (WAMS) applications. Commercial PMUs comes with many constraints such as cost, proprietary hardware designs and software. All these constraints have limited the deployment of PMUs at high voltage transmission systems alone. This paper addresses the issues by developing a cost-effective PMU with opensource hardware, which can be easily modified as per the requirements of the applications. The proposed device is tested with IEEE standards.
\end{abstract}

This is an open access article under the CC BY-SA license.

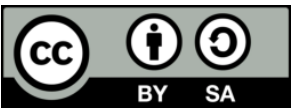

Corresponding Author:

V. Vijaya Rama Raju

Electrical and Electronics Engineering Department

Gokaraju Rangaraju Institute of Engineering and Technology (GRIET)

Bachupally, Hyderabad, Telangana state, 500090, India

Email: vijayram_v@yahoo.com

\section{INTRODUCTION}

In the early 1970s minicomputers were used for executing relay algorithms, but it was found very difficult to implement distance relaying algorithms due to delays in execution of instruction time. To overcome this problem Phadke et al. [1] proposed the use of symmetrical components of voltages and currents to implement distance relay algorithms. This has led to the development of first phasor measurement unit (PMU) in 1988 by them at Virginia Tech [2], [3]. Since then, synchrophasor technology has gained impetus and the technology got matured over the period and proved with large number of use cases across the globe. Motivation behind the momentum for the implementation of this technology was the occurrence of major blackouts across the globe. Blackout on 30 and 31 July 2012 that has affected most of northern and eastern parts of India is one such example [4]. These blackouts have forced to utilise the synchrophasor data from the PMUs deployed in wide area measurement systems (WAMS). 
First commercial PMU was brought out by Macrodyne Inc. in 1991, but the applications were limited because of high price tag. As a result, they were installed exclusively in high voltage transmission systems where bulk power transfer takes place. The implementation of wide-area backup security is one of the first applications to consider. Following that, researchers began looking into how time-tagged synchrophasor data could be used to improve voltage stability, State Estimation, and system security, among other things as described in [5]-[11]. Though, the initial installations found in bonneville power administration (BPA) substations of Pacific Northwest, the New York Power Authority and the American Electric Power Service Corporation of United States of America, within a short period they were installed across the utilities worldwide. European transmission system operators (TSOs) have started installation of PMUs in their WAM systems for monitoring voltage stability, phase angle difference of voltages, system damping and line thermal monitoring in 2003 [12]. Other installations include China's WAMS started in 2006, Japan, India, Russia, South Africa, Brazil, Mexico, and Australia. After the 2012 blackout in India, the biggest WAMS in the world came up with unified real time dynamic state measurement system (URTDSM) project. It is proposed to install one thousand nine hundred and fifty PMUs in three hundred and fifty one electric substations spread across India. In a hierarchical order, these PMUs located in the substations send synchrophasor data from 29 State Load Dispatch Centres to 5 Regional Load Dispatch Centres, and finally to National Load Dispatch Centre. At the national level, the project was planned to accommodate up to 3,000 PMUs in the future [13]. One of the major challenges identified in the deployment of PMUs is the financial constraint because of size of the system i.e., number of nodes present across the country [14].

Most of these projects are utilising the commercially available PMUs manufactured by different vendors spread across the world, including the leading players such as Schweitzer Engineering Laboratories (SEL), Siemens, Macrodyne, ABB, ALSTOM, General Electric Company (GE), and Mehta Tech, Typical cost of PMUs varies around $\$ 40,000$ to $\$ 180,000$ USD including procurement and installation. Several second and third world countries are not able to afford for the deployment of PMUs in their respective power grids due to exorbitant prices. One more challenge with commercial PMUs is the proprietary approach of the manufacturers. Commercial manufacturers protect their hardware and software designs with copyright or patent laws. Even the algorithms used for estimation of synchrophasors were not disclosed. These constraints have forced the researchers to come up with their own hardware designs and software. Some of these designs discussed in [15]-[19] include commercial hardware and software like LabVIEW.

This has led the researchers to explore the options for the development of an open hardware platform that can be redesigned as per the needs of the client requirements. Developing a low-cost hardware platform for PMUs was difficult in the earlier days. However, the advancements in technology and availability of low cost and high performing micro-controllers paved the path for the development of costeffective PMUs. As a result, a design effort is made to develop an economical PMU that can produce phasor magnitudes, angles, along with frequency and rate of change of frequency (ROCOF) for a three-phase system.

The following is a breakdown of how this paper is structured. Necessity for the development of open-source PMU, availability of PMUs in the market and literature available to understand about PMU applications are discussed in section 1. In section 2, definitions of synchrophasor components and IEEE standards for PMU are discussed. Methodology used for evaluating synchrophasors is described in section 3. Then, the development of PMU using hardware and software that is open-source is explained in section 4. Proposed hardware was tested in the laboratory and results were discussed in section 5. Finally, concluding remarks from the understanding were presented in section 6.

\section{SYNCHROPHASOR MEASUREMENTS AND PMU STANDARDS}

In power systems, voltage and current signals are sinusoidal. Ever since the concept of 'Phasor' introduced by Charles Proteus Steinmetz in 1893, power system networks are analysed using phasors that represent sinusoidal voltages and currents using vectors in complex plane with magnitude and phase angles as explained below. Time varying sinusoidal voltage signals are normally written by using the (1).

$$
v(t)=V_{m} \cos (\omega t+\theta)
$$

To simplify the analysis, these time domain signals are transformed to frequency domain signals and represented in terms of magnitudes and phase angles as mentioned in the (2).

$$
\begin{aligned}
& V=\left(\frac{V_{m}}{\sqrt{2}}\right) e^{j \theta} \\
& =\left(\frac{V_{m}}{\sqrt{2}}\right)(\cos (\theta)+j \sin (\theta)) \\
& =\left(V_{r}+j V_{i}\right)
\end{aligned}
$$


Where $\left(\frac{V_{m}}{\sqrt{2}}\right)$ is magnitude and $\theta$ is phase angle of the phasor. Time instant at the starting i.e., $\mathrm{t}=0$ of the sinusoidal decides the value of phase angle which is arbitrary. Whereas the phase angle difference is completely independent of the beginning time. So, same angular frequency needs to be considered while evaluating the other phasors. Angular frequency $\omega$ remains same during the evaluation of the other phasors in the network.

Following procedure is used in order to evaluate the synchrophasor for the voltage signal represented by (1). As per IEEE Std C37.118.1-2011, a reference cosine signal operating at nominal system frequency is used to calculate phase angle ' $\theta$ '. The reference signal is synchronized with coordinated universal time (UTC).

Sinusoidal voltage signal at nominal frequency ' $f_{0}^{\prime}$ ' can be represented as;

$$
v(t)=V_{m} \cos \left(\omega_{0} t+\theta\right)=V_{m} \cos \left(2 \pi f_{0} t+\theta\right)
$$

whereas the magnitude as well as frequency are time varying in real time, hence (3) is revised as;

$$
v(t)=V_{m}(t) \cos \left(2 \pi f_{0} t+\left(2 \pi \int x d t+\theta\right)\right)
$$

where $x(t)=f(t)-f_{0}$, variation of real time frequency with nominal frequency. The revised voltage equation given in (4) can be represented as synchrophasor by the (5).

$$
V(t)=\left(\frac{V_{m(t)}}{\sqrt{2}}\right) e^{j\left(2 \pi \int x d t+\theta\right)}
$$

System operators are also interested in knowing about the values of frequency and ROCOF, to implement protection functionalities like identification of under frequency condition, loss of mains condition and others. If the augment of the cosine function of voltage signal is represented by (6).

$$
\emptyset(t)=\omega_{0}(t)+\theta(t)=2 \pi f_{0} t+\theta(t)
$$

Frequency is calculated using;

$$
f(t)=\frac{1}{2 \pi} \frac{d \emptyset(t)}{d t}=f_{0}+d \frac{d\left[\frac{\theta(t)}{2 \pi}\right]}{d t}=f_{0}+\Delta f(t)
$$

where, nominal frequency is denoted by ' $f_{0}$ ' and variation of real time frequency with nominal frequency is considered as ' $\Delta f(t)$ '. ROCOF can be calculated from frequency as given by (8).

$$
\operatorname{ROCOF}(t)=\frac{d f(t)}{d t}
$$

All these parameters with GPS time tag are packed into a frame known as synchrophasors. These synchrophasors find numerous uses in different areas of electrical networks such as operations, security and control. In the beginning, because of restricted bandwidth, high latencies, and high-priced communication channels this synchrophasor data was used mostly for post-event analysis. Following that, researchers used this data to estimate parameters or validate models. Frequency monitoring across wide area become reality with frequency measurements and also helped in identification of possible loss of mains in the system. In conventional State Estimation process magnitudes and angles of voltages are estimated utilizing the line power flows, as well as real and reactive power injections at the buses. Previously, the state of the system was calculated rather than measured. Although measurements are scanned through out the system, the system's state is presumed to be static. Whereas power systems are operated completely dynamic in nature. High price tags of PMUs forced the researchers to investigate the optimal locations for the complete observability of the electric network [20]-[27].

To ensure the interoperability, several standards were brought out for the power sector operators to utilize time-tagged data across the network. IEEE has published a standard in 2005, IEEE C37.118-2005 [28] that ensures interoperability of the PMUs across the networks. The standard comprises a definition for synchronised phasor and the procedure for computing the phasors. A quality index, total vector error (TVE) was also included in the same standard. Later in 2011, this standard was updated in two parts. Synchrophasor estimation and certification requirements under both static and dynamic conditions are presented in the first part i.e., IEEE Std. C37.118.1 [29] and particulars about data representation and how the synchrophasor data 
can be communicated among the power system components are presented in second part i.e., IEEE Std. C37.118.2 [30].

\section{EVALUATION OF SYNCHROPHASORS}

Use of PMUs that provide synchrophasors is rising gradually. Application areas include monitoring of power system dynamics, post event recording in case of faults and so on. With the increased usage of these devices' commercial vendors and research organizations across the world proposed various models with limited utilization either due to commercial viability or proprietary restrictions. These problems have become the blocks for the extensive placement of these devices in the field. Each of these devices is capable of sending the following parameters to the central PDC with a GPS time tag in a more precise and efficient manner.

- Voltage and/or current phasors

- Frequency

- $\quad$ Rate of change of frequency (ROCOF)

Therefore, the development of a low-cost PMU capable of producing time-synchronized phasors is proposed.This can augment the smart grid initiative by deploying a greater number of PMUs at the strategic locations in the network so that the dynamics of the system can be observed. Procedures followed for phasors computation, frequency and ROCOF computations are as discussed below.

\subsection{Computation of phasors}

Discrete fourier transform (DFT) algorithm is considered to estimate the phasors by processing the sampled data. Equivalent phasor for the sinusoidal voltage mentioned by (4) can be computed with DFT algorithm as expressed by (6).

$$
V(j)=\frac{\sqrt{2}}{N} \sum_{m=0}^{N-1} v(j+m) e^{-j 2 \pi\left(\frac{m}{N}\right)}=V_{r}(j)-j V_{i}(j)
$$

Where,

$$
V_{r}(j)=\frac{\sqrt{2}}{N} \sum_{m=0}^{N-1} v(j+m) \operatorname{Cos}\left(2 \pi\left(\frac{m}{N}\right)\right) ; V_{i}(j)=\frac{\sqrt{2}}{N} \sum_{m=0}^{N-1} v(j+m) \operatorname{Sin}\left(2 \pi\left(\frac{m}{N}\right)\right)
$$

'N' representing total number of samples in a cycle and

' $\mathrm{j}$ ' representing sample number within the data window.

While evaluating the phasor data frame considers fixed number of samples by allowing the recent sample and discarding the first sample, thus making it recursive. To sample the data, device clocks were set to multiples of fundamental frequency.

\subsection{Computation of frequency (f) and ROCOF}

Frequency (f) can be computed from phasor angles. The value of Phase angle at any given time instant is given by;

$$
\theta(t)=\int \omega(t) d t=\frac{1}{2} \omega^{\prime} t^{2}+\Delta \omega t+\theta_{0}
$$

where, angular frequency in radians is $\omega(t)$, nominal frequency is $\omega_{0}$, variation in frequency is $\Delta \omega$ and the rate of change of frequency is $\omega^{\prime}$. If all these angles are measured at a sampling time of ' $\mathrm{T}_{\mathrm{s}}$ ' then a set of anglesare obtained as expressed in terms of $\theta_{0}, \Delta \omega$ and $\omega^{\prime}$ as given below:

$$
[\theta]=[A][\omega]
$$

where

$$
[\theta]=\left[\begin{array}{c}
\theta_{0} \\
\theta_{1} \\
\theta_{2} \\
\vdots \\
\theta_{N-1}
\end{array}\right] ; \quad[A]=\left[\begin{array}{rrr}
1 & 0 & 0 \\
1 & T_{s} & T_{s}^{2} \\
1 & 2 T_{s} & 2 T_{s}^{2} \\
\vdots & \vdots & \vdots \\
1 & (N-1) T_{s} & (N-1) T_{s}^{2}
\end{array}\right] ; \quad[\omega]=\left[\begin{array}{c}
\theta_{0} \\
\Delta \omega \\
\omega^{\prime}
\end{array}\right]
$$


By solving (11), $\Delta \omega$ and $\omega^{\prime}$ can be computed:

$$
[\omega]=\left[\mathrm{A} \mathrm{A}^{\mathrm{T}}\right]^{-1}[\mathrm{~A}][\theta]
$$

After obtaining the values of $\Delta \omega$ and $\omega^{\prime}$, Frequency (f) and ROCOF can be found as;

$$
f(t)=\theta^{\prime}(t)
$$

and

$$
\text { ROCOF }=\frac{\omega^{\prime}}{2 \pi}
$$

These algorithms are implemented on open-source hardware, as outlined in the following section, allowing researchers to expand and change them to meet their specific needs while avoiding proprietary barriers.

\section{HARDWARE EXECUTION}

Entire execution of a Phasor measurement unit is developed by utilizing off-the-shelf open-source hardware available in the market. Figure 1 describes the implementation of PMU using hardware setup. This consists of five major modules namely, Three-phase voltage sensor module, Arduino Due, GPS module, Frequency measurement module and Power supply module.

\subsection{Three phase voltage sensor module}

At the sub-station level, voltages from the potential transformers are fed to this module after signal conditioning. This module consists of three ZMPT $101 \mathrm{~B}$ Voltage transformers that will further step down the voltages to $3.3 \mathrm{~V}$ suitable for sampling using Arduino due. Op-amp circuits present in the module helps in accurate sampling of sinusoidal signals. Sampling of these three phase signals will be initiated by the Arduino due after receiving 1 pulse per second (1PPS) signal from the GPS module.

\subsection{Arduino due}

An Atmel SAM3X8E microcontroller board with ARM Cortex-M3 CPU and 32-bit ARM core is used as phasor calculation unit. To sample the three phase voltage signals, $84 \mathrm{MHz}$ clock of this board is synchronized with the 1 PPS obtained from GPS module. This clock frequency is adequate to estimate the synchrophasors, as 64 samples/ cycle are used to calculate the voltage phasors. Another rational behind the selection of this board is, the in-built 12-bit ADC. This can easily convert the sampled data at the said rate. Sampling of 3-phase voltages start once it receives an interrupt from the GPS module. Each time a sample is received by the Due, it is stored in the RAM and initiates a counter that counts till the end of 64 samples. After receiving the 64 samples, the processor will start calculating the voltage phasor using the DFT algorithm detailed in section 3. Along with the phasor calculations, frequency and ROCOF are also calculated from the pulse train received from the frequency measurement module explained in the following sub-section. After evaluating all the parameters, they are forwarded to phasor data concentrator (PDC) with the GPS time stamp received from GPS module.

\subsection{GPS module}

This module provides the 1PPS signal to the Due to synchronize the clock with UTC as well as to initiate the sampling process. As per the IEEE standard C37.118.1-2011 the phasor calculator (Arduino Due) has to generate a maximum of 50 frames per cycle for a typical $50 \mathrm{~Hz}$ sinusoidal signal. After receiving the 1 PPS signal from this module, Due generates a pulse train used for sampling the signals. NEO-6M GPS module is chosen based on its performance, cost-effectiveness, and ease of interface with the microcontroller boards.

\subsection{Frequency measurement module}

This module is used to determine the frequency of the 3-phase voltage signals from the PTs. The three-phase AC voltage signals are stepped down to $3.3 \mathrm{~V}$ signals and rectified using half-wave bridge rectifier. Rectified signals are then fed to optocouplers to convert them into a pulse train. These pulses are given to the interrupt pins of Due. Whenever these pins become high, Due calculates the time difference between the subsequent interrupt signals and evaluates the frequency. After calculating the frequency, Due evaluates the ROCOF using the algorithm mentioned in section 3. 


\subsection{Power supply module}

Different components like ZMPT 101 B voltage transformers, optocouplers in frequency measurement module and GPS module require regulated $3.3 \mathrm{~V}$ DC power. Single-phase, $230 \mathrm{~V}, 50 \mathrm{~Hz} \mathrm{AC}$ supply is stepped down to $9 \mathrm{~V}$ and rectified using full bridge rectifier. Smoothing capacitors are used to filter the rectifier output for ripples. To regulate the voltage to the desired value of $3.3 \mathrm{~V}$, DC-DC buck converter module is connected at the output of the smoothing capacitor. This module can drive up to 3 A load with good voltage regulation.

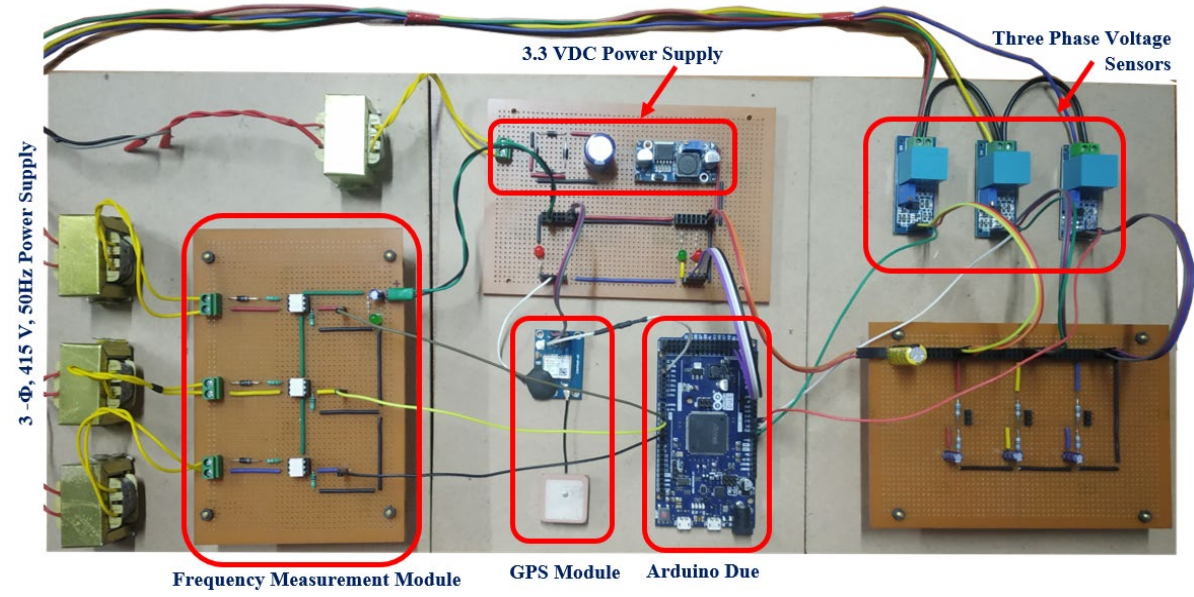

Figure 1. PMU hardware setup

\section{RESULTS AND DISCUSSION}

Proposed PMU is tested with 3-phase, $415 \mathrm{~V}, 50 \mathrm{~Hz}$ power supply in the laboratory. Three phase voltages are stepped down to $3.3 \mathrm{~V}$ as mandated by the phasor estimator using the voltage sensor module. These are sampled with a sampling frequency of $3.2 \mathrm{kHz}$ after receiving 1 PPS signal from GPS module. Phasor calculator, Arduino Due in this case gathers 64 samples per cycle of sinusoidal signal and stores in the buffer, after it receives an interrupt signal from the GPS module. Then it performs the DFT algorithm to calculate the phasor magnitudes and angles of all the three phases. Figures 2 and 3 respectively show the calculated magnitudes and angles for a duration of 1 second time interval i.e., 50 frames as per IEEE standard.

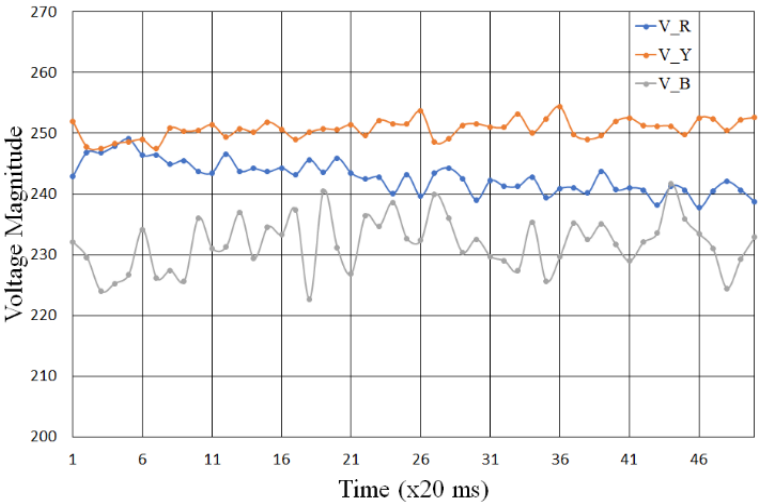

Figure 2. Variation of voltage phasor magnitude with time

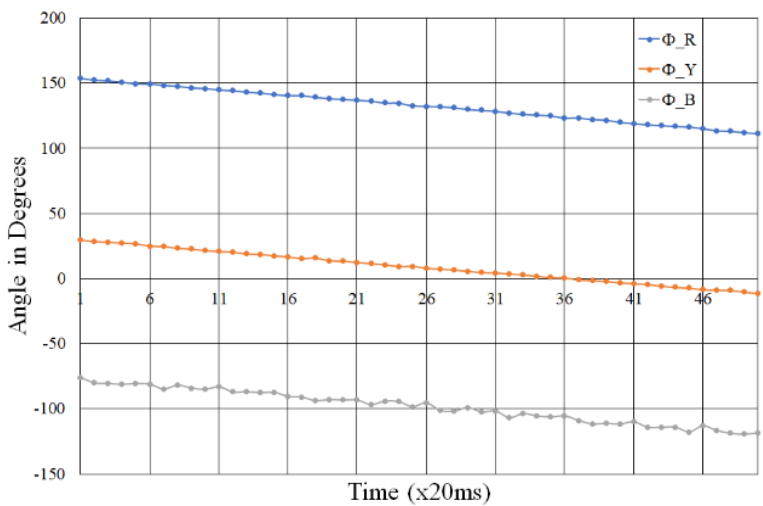

Figure 3. Variation of voltage phasor angles with time

Along with the phasor calculations Arduino due will also perform the calculation of frequency and ROCOF. To calculate the frequency, three-phase voltages are stepped down and converted into pulses using the rectifier and optocoupler circuit described in section 4.4. Based on time period of the pulses, Due 
calculates the frequency. As the test signals are considered from the real time power outlet the frequency varies continuously based on the load variations in the grid as shown in the Figure 4.

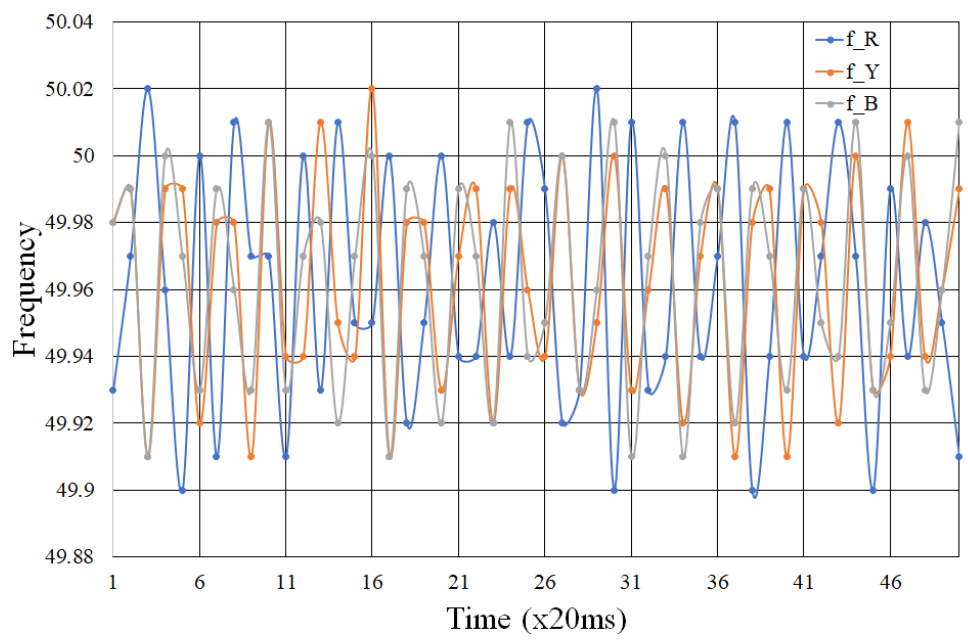

Figure 4. Variation of frequency with time

Another important parameter that is used as a measure of power system inertia is ROCOF. This is majorly used for the identification of loss of mains. PMU also calculates this parameter from the values of frequency using the algorithm mentioned in the section 2. All these 12 parameters measured for a 3-phase are put in a frame and tagged with timestamp and date along with the longitude and latitude. In accordance with the IEEE C37.118.1-2011 standard, the reporting rates for a $50 \mathrm{~Hz}$ sinusoidal signal are 10, 25 and 50 frames per second. So, the proposed PMU was designed to generate 50 Frames per second considering $50 \mathrm{~Hz} \mathrm{AC}$ test signal. Test results are tabulated in Table 1. Proposed PMU which is developed by using the most sought after, lucrative, cost-effective and open-source hardware and software is able to estimate the synchrophasors for the real time three-phase voltages as per the standards.

Table 1. Three-phase Synchrophasor voltages with magnitudes, angles, frequency, ROCOF along with GPS time stamp and date

\begin{tabular}{|c|c|c|c|c|c|c|c|c|c|c|c|c|c|c|}
\hline $\begin{array}{c}\text { Frame } \\
\text { No }\end{array}$ & $V_{-} R$ & $\Phi \_R$ & $\mathrm{f}_{-} \mathrm{R}$ & ROCOF_R & V_Y & $\Phi \_\mathrm{Y}$ & $\mathrm{f}_{-} \mathrm{Y}$ & ROCOF_Y & V_B & $\Phi \_B$ & f_B & ROCOF_B & Time Stamp & Date \\
\hline 2 & 246.85 & 152.5 & 49.97 & 2 & 247.73 & 28.54 & 49.99 & 0.5 & 229.58 & -80.05 & 49.99 & 0.5 & 11:46:55:040168 & 10:11:20 \\
\hline 3 & 246.76 & 151.83 & 50.02 & 2.5 & 247.48 & 27.84 & 49.91 & -4 & 223.99 & -80.5 & 49.91 & -4 & $11: 46: 55: 060136$ & 10:11:20 \\
\hline 5 & 249.05 & 149.59 & 49.9 & -3 & 248.59 & 26.66 & 49.99 & 0 & 226.7 & -80.57 & 49.97 & -1.5 & $11: 46: 55: 110072$ & 10:11:20 \\
\hline 6 & 246.39 & 149.38 & 50 & 5 & 248.91 & 25.01 & 49.92 & -3.5 & 234.12 & -81.1 & 49.93 & -2 & $11: 46: 55: 120040$ & 10:11:20 \\
\hline 7 & 246.45 & 148.46 & 49.91 & -4.5 & 247.43 & 24.61 & 49.98 & 3 & 226.15 & -84.71 & 49.99 & 3 & $11: 46: 55: 140008$ & 10:11:20 \\
\hline 8 & 244.92 & 147.74 & 50.01 & 5 & 250.83 & 23.38 & 49.98 & 0 & 227.41 & -81.75 & 49.96 & -1.5 & $11: 46: 55: 159976$ & $10: 11: 20$ \\
\hline
\end{tabular}

\section{CONCLUSION}

PMUs are increasingly being used in wide-area monitoring and control of power systems in both static and dynamic environments. Whereas the constraints like high price tags and proprietary designs limited the widespread use of these devices in the field. Contemplating all these limitations, more affordable device using open-source hardware to measure synchrophasors is proposed and tested as per IEEE standards. This device can generate 50 frames per second, each frame consisting of 3-phase voltage phasor magnitudes, angles, frequencies and ROCOFs along with GPS time tag, date and location parameters longitude and latitudes. Cost as well as the number of components used in the proposed design justifies the costeffectiveness of the device. Use of open-source hardware and software like Arduino encourage the researchers to further enhance the value of the device by adding different functionalities like protection and measurements. Lucrative price tag will allow the utilities to deploy a greater number of devices from transmission to distribution level to move forward and make the existing grid as smart grid. 


\section{REFERENCES}

[1] A. G. Phadke, T. Hlibka, M. Ibrahim, and M. G. Adamiak, "A Microcomputer Based Symmetrical Component Distance Relay," IEEE Conference Proceedings Power Industry Computer Applications Conference, PICA-79, 1979, pp. 47-55, doi: 10.1109/PICA.1979.720045.

[2] A. G. Phadke, "Synchronized phasor measurements in power systems," IEEE Computer Applications in Power, vol. 6, no. 2, pp. 10-15, 1993, doi: 10.1109/67.207465.

[3] J. D. L. Ree, V. Centeno, J. S. Thorp, A. G. Phadke, "Synchronized Phasor Measurement Applications in Power Systems," IEEE Transactions on Smart Grid, vol. 1, no. 1, pp. 20-27, 2010, doi: 10.1109/TSG.2010.2044815.

[4] "Report on the Grid Disturbances on 30th July and 31st July 2012," 2012, [Online]. Available: http://www.cercind.gov.in/2012/orders/final_report_grid_disturbance.pdf.

[5] S. Dasgupta, M. Paramasivam, U. Vaidya, and V. Ajjarapu, "Real-Time Monitoring of Short-Term Voltage Stability Using PMU Data," IEEE Transactions on Power Systems, vol. 28, no. 4, pp. 3702 -3711, 2013, doi: 10.1109/TPWRS.2013.2258946.

[6] F. Aminifar, M. Shahidehpour, M. F.-Firuzabad, and S. Kamalinia, "Power System Dynamic State Estimation With Synchronized Phasor Measurements," IEEE Transactions on Instrumentation and Measurement, vol. 63, no. 2, pp. 352-363, 2014. 10.1109/TIM.2013.2278595.

[7] F. Hu, K. Sun, D. Shi, and Z. Wang, "Measurement-based voltage stability assessment for load areas addressing n-1 contingencies," IET Generation Transmission \& Distribution, vol. 11, no. 15, pp. 3731-3738, 2017, doi: 10.1049/iet-gtd.2016.1913

[8] V. Nougain, M. K. Jena, and B. K. Panigrahi, "Synchro-phasors Assisted Back-up Protection of Transmission Line," IET Generation, Transmission \& Distribution, vol. 12 , no. 14, pp. 3414-3420, 2018, doi:10.1049/ietgtd.2017.1711

[9] P. V. Navalkar, and S. A. Soman, "Secure Remote Backup Protection of Transmission Lines Using Synchrophasors," IEEE Transactions on Power Delivery, vol. 26, no. 1, pp. 87-96, 2011, doi: 10.1109/TPWRD.2010.2076350

[10] L. M. A. El-Sayed, D. K. Ibrahim, M. Gilany, A.'F. El'Gharably, “An accurate technique for supervising distance relays during power swing," Indonesian Indonesian Journal of Electrical Engineering and Computer Science (IJEECS), vol. 21, no. 3, pp. 1279-1290, 2021, doi: 10.11591/ijeecs.v21.i3.pp1279-1290.

[11] K. Arpit, T. Ankush, and S. Akash, "Power System State Estimation by Novel Approach of Kalman Filter," Indonesian Indonesian Journal of Electrical Engineering and Computer Science (IJEECS), vol. 6, no. 2, pp. 241-253, 2017, doi: 10.11591/ijeecs.v6.i2.pp241-253.

[12] W. Sattinger, "Application of PMU measurements in Europe TSO approach and experience," 2011 IEEE Trondheim PowerTech, Trondheim, Norway, 2011, pp. 1-4, doi: 10.1109/PTC.2011.6019250.

[13] P. J. Harding, A. Varghese, R. Bharat, A. Gillies, and G. Lloyd, "Implementation of a wide-area monitoring scheme for the Indian power system," 13th International Conference on Development in Power System Protection 2016 (DPSP), Edinburgh, UK, 2016, pp. 1-6, doi: 10.1049/cp.2016.0075.

[14] A. A. A. Marwan, M. Zuhaib, and M. Rihan, "An investigation on the application and challenges for wide area monitoring and control in smart grid," Bulletin of Electrical Engineering and Informatics (BEEI), vol. 10, no. 2, pp. 580-587, 2020, doi: 10.11591/eei.v10i2.2767.

[15] C. Andrea, N. Locci, C. Muscas, and S. Sulis, "A flexible GPS-based system for synchronized phasor measurement in electric distribution networks," IEEE transactions on instrumentation and measurement, vol. 57, no. 11, pp. 2450-2456, 2008, doi: 10.1109/TIM.2008.924930.

[16] "Open Source Phasor Data Concentrator" Grid Protection Alliance, [Online]. Available: https://github.com/GridProtectionAlliance/openPDC.

[17] A. J. Stadlin, "GridTrak Open Source Synchrophasor PMU Project," [Online]. Available: https://archive.codeplex.com/?p=gridtrak.

[18] G.-Valle, G.-Ya Yang, K. E. Martin, A. H. Nielsen, and J. Østergaard, "DTU PMU laboratory development, Testing and validation," 2010 IEEE PES Innovative Smart Grid Technologies Conference Europe (ISGT Europe), 2010, pp. 1-6, doi: 10.1109/ISGTEUROPE.2010.5638883.

[19] A. H. Nielsen, K. Pedersen, and Olof Samuelsson, "An experimental GPS-based measurement unit," Proc. of Nordic Baltic Workshop Power Systems, Finland, 2002, pp. 1-6.

[20] V. V. R. Raju and S. V. Jayarama Kumar, "An Optimal PMU Placement method for Power System Observability," 2016 IEEE Power and Energy Conference at Illinois (PECI), USA, 2016, doi: 10.1109/PECI.2016.7459248.

[21] B. Gou, "Optimal Placement of PMUs by Integer Linear Programming," IEEE Transactions on Power Systems, vol. 23, no. 3, pp. 1525-1526, 2008, doi: 10.1109/TPWRS.2008.926723.

[22] B. Gou, "Generalized integer linear programming formulation for optimal PMU placement," IEEE Transactions on Power Systems, vol. 23, no. 3, pp. 1099-1104, 2008, doi: 10.1109/TPWRS.2008.926475.

[23] C. Rakpenthai, S. Premrudeepreechacharn, S. Uatrongjit, and N. R. Watson, "An optimal PMU placement method against measurement loss and branch outage," IEEE transactions on power delivery, vol. 22, no. 1, pp. 101-107, 2005, doi: 10.1109/TPWRD.2006.881425.

[24] S. Chakrabarti and E. Kyriakides, "Optimal placement of phasor measurement units for power system observability," IEEE Transactions on Power Systems, vol. 23, no. 3, pp. 1433-1440, 2008, doi: 10.1109/TPWRS.2008.922621.

[25] D. Devesh, S. Dambhare, R. K. Gajbhiye, and S. A. Soman, "Optimal multistage scheduling of PMU placement: An ILP approach,” IEEE Transactions on Power Delivery, vol. 23, no. 4, pp. 1812-1820, 2006. 
[26] K. Deebiga, A. R. Hussain, "Optimal Placement of Phasor Measurement Unit for Better Power System Observability," TELKOMNIKA Indonesian Journal of Electrical Engineering, vol. 14, no. 2, pp. 199-204, 2015, doi: 10.11591/telkomnika.v14i2.7605.

[27] M. Baba, N. B. M. Nor, T. B. Ibrahim, M. A. Sheikh, "A comprehensive review for optimal placement of phasor measurement unit for network observability," Indonesian Journal of Electrical Engineering and Computer Science (IJEECS), vol. 19, no. 1, pp. 301-308, 2020, doi: 10.11591/ijeecs.v19.i1.pp301-308

[28] "IEEE Std. C37.118-2005, IEEE Standard for Synchronized Phasor Measurements for Power Systems," 2006, doi: 10.1109/IEEESTD.2006.99376.

[29] "IEEE Std C37.118.1-2011. IEEE Standard for Synchrophasor Measurements for Power Systems," IEEE Power \& Energy Society, 2011, doi: 10.1109/IEEESTD.2011.6111219.

[30] “IEEE Std C37.118.2-2011-IEEE Standard for Synchrophasor Data Transfer for Power Systems," IEEE Power and Energy Society, 2011, doi: 10.1109/IEEESTD.2011.6111222.

\section{BIOGRAPHIES OF AUTHORS}

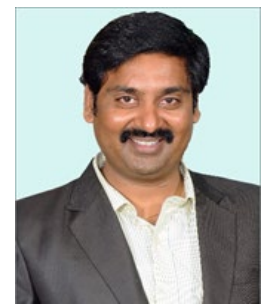

V. Vijaya Rama Raju got his master's degree from National Institute of Technology Warangal (NITW) in the year 2001 with Power Systems specialization. During his master's program he has developed various control algorithms for FACTS devices while working in Electrical Research and Development Association (ERDA), Baroda. He is currently a Senior member of IEEE, recognized as Chartered Engineer (India) by IE (India) and also a Fellow member of Institution of Engineers India. Currently pursuing Ph.D in the area of synchrophasor technology and published several papers in international conferences and journals. His research areas are Smart Grids and Renewable Energy systems. At present he is working as Associate Professor in the department of Electrical and Electronics Engineering, GRIET, Hyderabad, India.

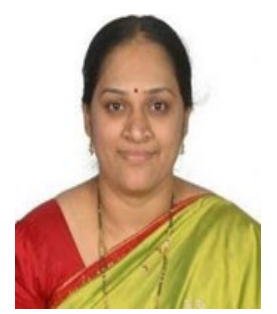

K. H. Phani shree pursued her Master's Degree in Power systems from NIT Trichurapalli and Doctoral Degree from JNTU Hderabad. She has 18 years of experience in both teaching and research. For her contributions in power electronics she was awarded with Engineering Impact Award by National Instruments in the year 2016. She is a Member of IEEE \& ISTE. Established Research Lab in EEE department of JNTU. Her research findings were published in 12 journals. She has guided 25 PG and 20 UG Projects. Currently guiding 3 Ph.D scholars. At present, she is working as Associate Professor in EEE dept. of JNTUH College of Engineering Hyderabad. Her research areas are Power Electronics and Drives, FACTS, and Renewable energy systems.

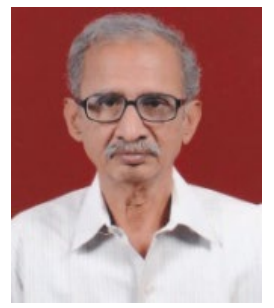

S. V. Jayaram Kumar pursued his master's degree in Electrical Engineering from Andhra University, Vishakapatnam, India in the year 1979. He has received Doctoral degree in Electrical Engineering from IIT, Kanpur, in the year 2000. He has retired as Professor from Jawaharlal Nehru Technological University Hyderabad with more than 30 years of teaching and research experience. His research areas are Power System Dynamics and FACTS controllers. 